\title{
Analysis of Beam-Column Joints using FEM
}

\author{
Ch. Harika ${ }^{1}$ and Dr. N. Murali Krishna ${ }^{2}$ \\ ${ }^{1}$ Asst. Professor, CVR College of Engineering/Civil Engg. Department, Hyderabad, India \\ Email: harikareddy2771995@gmail.com \\ ${ }^{2}$ Professor, CVR College of Engineering/Civil Engg. Department, Hyderabad, India \\ Email: nmuralikrishna1956@gmail.com
}

\begin{abstract}
Members of space frame structures are in general subjected to axial force, biaxial shear, biaxial moments and torque. The structural designing of frameworks are carried-out so as to meet the critical stress levels of each individual structural member. In this context even though the sectional sizes of the individual members are adequate to withstand the forces they carry, the junctions where many such members meet, may not be adequate to withstand the combined effects. This problem is common to all kinds of structural joints made up of both steel and concrete.

In the present paper the beam-column junction portion made in RCC is analyzed using the FEM package ANSYS. The loads that act at the beam-column joint are obtained from the output of structural analysis of framed structure. These loads are used on the FEM model of beam-column joint. The aim of the present study is to replace the beam-column joint in a structural frame work with the equivalent strut-beam frame work to carry out the structural analysis. By this approach it is intended to use the same software package used for the analysis of skeletal frame work to the one with the beam-column joints also.
\end{abstract}

Index Terms: Beam-column joint, equivalent strut, axial force, shear and torque.

\section{INTRODUCTION}

Structural designing of a framed structure involves the design of slabs, beams, columns and footings. The design of slabs and footings do not interfere with the designing of beams and columns but the reverse is not always true. In the RCC limit state method of structural design, the beams are checked against their capacity to with-stand the combined effect of maximum bending moment and maximum the shear-force, that comes on to them. The structural design of column elements on the other-hand is verified against the combined effect of maximum axial force and the biaxial moments.

The present practice of structural designing is considered adequate if the structural designing concepts of individual elements are safe. Their combined action near the joint where more than one member meets is never checked. As on date, there exists no formal procedure to evaluate the magnitude of structural distress that comes due to the combined action from different elements meeting near the joint. If the joint is between beam and column elements it is called a beam-column joint. Hence, even through the individual structural elements are found safe, the joint where they are connected may not be always safe since it is not checked. Apart from this, the structural analysis of beamcolumn joint is never an integral part of any current structural analysis/design software packages.

Due to the above reasons, in-depth study on the structural analysis of beam-column joint is essential. The studies using analytical and experimental approaches needs to be carriedout and the results obtained shall be validated. The analytical approaches may be either classical or computational methods like finite difference/finite element methods. The experimental studies may be carried-out on either prototype models or scale models. Currently active research on the behavior of beam-column joints is being pursued all over the world.

\section{A. Need of the study}

As on date there exists no specific structural design methodology to check the safety of the beam-column joints. The reasons are due to the lack of information regarding composition of materials near joint, the non-availability of suitable theoretical concepts and the amount cumbersomeness involved in its implementation. However, the inability to verify the structural safety of beam/column joints can be quoted as an excuse in a comprehensive structural design. This leaves the overall stability of the structural system in doubt. This prompts the urgent need to take-up the research leading to estimate the structural distress in beam-column joints.

\section{B. Objective of the study}

Having appreciated well, the need to study the performance of beam-column joints, it is proposed to develop a simple model representing the behaviour of beamcolumn joints to evaluate the safety of the beam column joint in a framed structure. The model to be proposed shall be simple, amenable and adoptable with the conventional structural analysis packages dealing with discrete structures.

\section{LITERATURE REVIEW}

The studies on beam-column joints are on since early 1960 's. The studies in general may broadly be categorized as analytical or experimental or both. Most of the researchers have carried-out experiments on scale models of beam-column joints and have proposed analytical expressions to arrive at their strength and stiffness contributions. Some of the research works which have been carried-out since 2004 is presented below.

The FEM analysis of hybrid structural frames with reinforced concrete columns and steel beams was carried out 
by Hiroshi Noguchi and Kazuhiro Uchida. Two specimens, which had different beam-column joint detailing, were analyzed using the nonlinear three-dimensional finite element method. The failure process and shear resisting mechanisms of differently shaped beam-column joints (interior, exterior, interior top, and corner) were understood by analytical results of the stress-strain relationship among concrete elements, shear force of the beam-column joints, the contribution of shear resisting elements, and deformation components, which were not obtained in the experiment. [1]

The behavior of exterior beam column joints sub assemblages with transverse reinforcements detailed as per IS 456 and IS 13920 was compared by K.R. Bindhu, P.M. Sukumar and K.P. Jaya. A six storied RC building in Zone III was analyzed, and one of the exterior beam column joints at an intermediate storey was designed. The test specimen was reduced to $1 / 3^{\text {rd }}$ size of prototype. [2]

Rajaram, A. Murugesan and G.S.Thirugnanam had carried-out analytical and experimental studies on interior beam column joint subjected to cyclic loading. The model was subjected to cyclic loading to find its behavior during earthquake. The same model was analyzed by FEM analysis using ANSYS. The results from experiments were compared with those obtained from FEM model analyzed using ANSYS. It was concluded that experimental and analytical behavior of the interior beam column joint was in agreement. Based on the results obtained from their experiments, they had presented about the influence of parameters such as ductility, energy absorption, stiffness degradation etc., on beam/column joint in the event of seismic disturbance. [3]

Bing Li and Sudhakar A. Kulkarni carried out an experimental and numerical investigation on $\mathrm{RC}$ wide beamcolumn joints when subjected to seismic loads. The behavior of the joints under the influence of critical influencing factors like column axial load, transverse beam, and beam bar anchorage ratio were also analyzed through the parametric studies carried out. The DIANA software was used for the FE analysis. The concrete was modeled using 20-node 3D quadratic solid elements while the reinforcing bars were modeled as truss elements. [4]

An experimental and analytical investigation on the seismic behaviour of fibre reinforced polymer (FRP) and textile reinforced mortar (TRM) upgraded RC exterior beam column joints was carried out by Mohammad S. Alhaddad, Nadeem A. Siddiqui, Aref A. Abadel, Saleh H. Alsayed and Yousef A. Al-Salloum. The results obtained from the FEM analysis were compared with the test results, and it was observed that the FEM analysis predicts the satisfactory results with control specimen, FRP, TRM strengthened exterior RC beam column joint. [5]

The analytical study of reinforced beam column joint subjected to monotonic loading was investigated by S. S. Patil, S. S. Manekari. In this study ANSYS software was used for performing the FEM analysis of beam column joint. It was concluded that, the displacement, maximum stress and minimum stress values were observed to be less in fixed support condition of beam column joint when compared to hinge support condition. And the behaviour of corner and exterior joints are different. And as the stiffness of structure changes, the displacement, maximum stress and minimum stress changes Non-linearly. [6]

Finite element modelling of reinforced concrete beam column joint was carried out by Syed Sohailuddin S and M G Shaikh. The FEM analysis was done by ANSYS 11.0. All specimens were subjected to similar reverse cyclic loading to simulate the earthquake loading in structures. From this analysis it was found that the test specimen with diagonal confining bars of $8 \mathrm{~mm}$ in the beam region have shown better performance, exhibiting higher strength with minimum cracks in the joint. All the specimens failed by developing tensile cracks at interface between beam and column. [7]

The experimental findings of HSC interior beam column joints under column axial compressive loading were performed by Bing Li, M.ASCE and Chee Lai Leong. It was observed that HSC improved the bond condition of reinforcing bars of larger diameters. The various parameters influencing the strength and bond of HSC beam column joints were studied by parametric studies of FEM modelling. Based on test results and FE analysis, some relaxation of the bond requirements in beam-column joints is recommended when HSC is used because bond strength increases with the increase in concrete compressive strength. [8]

The experimental investigation of Hybrid Fibre Reinforced Concrete of Exterior Beam-Column Joint under Cyclic loading was done by C.Geethajali, P.Muthu Priya, Dr. R.Venkatasubramani. Results shown that the fibers when used in a hybrid form could result in superior composite performance compared to their individual fibrereinforced concretes. It was observed that the ultimate load carrying capacity increases by $38 \%$ for hybrid fibre when compared to steel fibre beam column joint specimen. [9]

The details of finite element analysis of beam column joints wrapped with glass fibre reinforced polymer sheets (GFRP) carried out by Shabana T S, K.A Abubaker, Renny Varghees using the package ANSYS were presented in this paper. ETABS was used for modelling and analysis of $\mathrm{G}+4$ office building. During the analysis both the ends of column were hinged. Static load was applied at the free end of the cantilever beam up to a controlled load. The percentage of increase in efficiency of wrapped over unwrapped was found to be $37 \%$ for beam column joint designed as per IS 456:2000 and 20\% for designed as per IS 13920:1993. [10] 


\section{Methodology}

\section{A. The Analysis and Design of RCC Building in ETABS}

The study is carryout by having a sample of beam-column joints with full data available regarding the sizes, materials and the loads. The data is possible only if a space framed building is analysed with the available geometric and load data. For the purpose of study an existing building frame data is obtained. With the data available the 3-D building frame model is developed using ETABS package and the linear static analysis of the structural frame is carried out using ETABS-17 package.

ETABS is a sophisticated, easy to use, special purpose analysis and design program developed specifically for building systems. ETABS 2017 features an intuitive and powerful graphical interface coupled with unmatched modelling, analytical, design, and detailing procedures, all integrated using a common database. Although quick and easy for simple structures, ETABS can also handle the largest and most complex building models, including a wide range of nonlinear behaviours necessary for performancebased design, making it the tool of choice for structural engineers in the building industry.

The following is the list of steps to be followed in ETABS for the analysis and design of a reinforced concrete building.

Step - 1: Opening Screen: Selection of base units and design codes

Step - 2: Creation of Grid points \& Generation of structure

Step - 3: Defining of material and section properties

Step - 4: Assigning of Property

Step - 5: Assigning of Supports

Step - 6: Defining of loads

Step - 7: Assigning of Dead loads

Step - 8: Assigning of Live loads

Step - 9: Assigning of load combinations

Step - 10: Analysis

Step - 11: Design

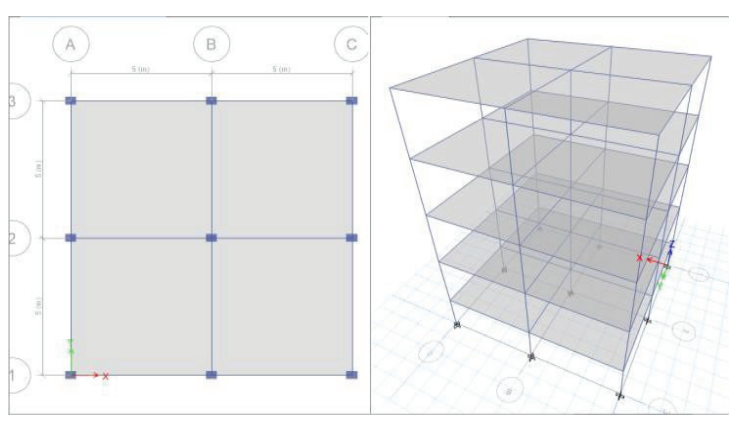

Figure 1. Plan and isometric view of RC building

\section{B. The FEM analysis in ANSYS}

The FEM analysis of beam-column joint is a very complicated task and hence, is undertaken as detailed below.
For the purpose of FEM analysis ANSYS software is used for the modelling of beam-column joint.

1. Pre-processer module

i) Geometric modelling of beam-column joint

ii) Element modelling

iii) Material modelling

iv) Meshing of the model

v) Loads and boundary conditions

2. Analysis Module

3. Post processer Module

The very purpose of the present research on beam-column joints is to propose a feasible method which may be simple to be adopted, yet accurate to represent the true behaviour of the beam-column joint. In this context the strain energy stored within the beam column interface comprising of the reinforced cement concrete is calculated first using the ANSYS software. The concrete mass in the beam-column joint location is replaced with the equivalent beam/strut concrete elements as described under. Along the interfaces of the beam-column joints square cross section members representing the beam elements are placed parallel to the beam and column orientations along the edges of the beamcolumn interfaces. Next, strut members of the same crosssectional area are placed joining the mid points of the beam and column surfaces. The material adopted for the both beam and strut elements are the same as that of the concrete representing the column members. The strain energy carried by such equivalent beam/strut concrete elements is calculated in combination with the beam- column elements once again using the ANSYS software. Equivalence in the energies between the two different models is not possible as the later one more flexible. The sizes of the members representing the equivalent beam/strut elements are revised using a penalty factor.

The intention of the present study is to terminate all the beam/column elements in a conventional structural analysis near the beam-column interfaces and introduce the equivalent beam/strut concrete elements within the beamcolumn interface. The connectivity beam/ column elements and the equivalent struts shall be established. There after the structural analysis may be carried out for the framed structure considering the revised beam/column elements and together with the equivalent beam/strut elements. This kind of treatment is considered more rational and hence acceptable. The complicated stress analysis to evaluate the condition of beam-column junction can be avoided.

The magnitude of the penalty factor is obtained by dividing the strain energy corresponding to the full concrete in the beam-column joint location with the strain energy due to the equivalent beam/strut model. The sizes of the members of the equivalent beam/strut elements are revised next upward based on the magnitude of the penalty factor. The magnitudes of the penalty factor differ depending on the size and grades of the concrete beam-column elements meeting at the joint. As evident due to the flexibility of the discrete beam/strut elements proposed the magnitude of the penalty factor is always larger than one. 
Such studies are to be carried out on different beamcolumn junctions by varying the sizes of sectional dimensions and grades of concrete. It is proposed to use the output of the results from a large set of such studies to train a neural net algorithm. The trained net facilitates obtaining the sizes of the equivalent beam/strut elements for any new beam-column joint. These beam/strut elements may be modelled in place of the beam-column joints in a conventional structural frame work to be designed using the structural design packages. Though conservative, the safety of the equivalent beam/strut elements ensures the safety of the beam-column joints.

\section{SPECIMEN CALCUlations}

In this present study the three types of beam-column joints are considered and the FEM analysis is carried out by ANSYS software. The ANSYS program has many finite element capabilities, ranging from a simple linear static analysis to the complex non linear transient dynamic analysis. In this chapter the three types of beam-column joints with and without the equivalent beam/strut elements varying the grade of concrete of beams/columns and varying the cross sectional dimensions of beams/columns are explained.

\section{Interior Beam-Column Joint}

The interior beam-column joint which is at fourth storey level is taken and the analysis is carried out in ETABS. The results obtained from ETABS analysis are used here to carry out the FEM analysis.

To model the interior beam-column joint the solid 185 element is taken. Solid 185 element is a $3 \mathrm{D}$ element with 8 nodes in it. It is used for 3D modelling of solid structures. It is defined by 8 nods having 3 degrees of freedom at each node; translations in the nodal $\mathrm{x}, \mathrm{y}$ and $\mathrm{z}$ directions.

For this analysis two material properties are taken. The first material property describes the properties of concrete such as young's modulus as $25 \mathrm{e} 3$ and poisons ratio as 0.3 . And the second material property describes the thin rigid plate which is having young's modulus as 2e10 and poisons ratio as 0.15 .

For the modelling of the interior beam-column joint solid modelling method is used. By this method, directly solid with volumes are created. The cross sectional dimension of the beams are taken as 300 X $500 \mathrm{~mm}$ and 400 X $500 \mathrm{~mm}$ and the cross sectional dimension of the column is taken as $300 \times 400 \mathrm{~mm}$. From the beam-column joint the beam extends to right, left and front, back sides by 1 metre. The thin rigid plates are attached to the faces of the beams and columns to transfer the loads uniformly.

By using mesh tool, mesh the geometry of the structure with the mapped volume mesh. The 1 metre length beams and columns are divided into ten element divisions and the dimensions of width of the column and depth of the beam are divided into eight element divisions and the depth of the column and width of the beam are divided into six element divisions. The thin rigid plate is attached to surface of beams/columns for load application are also divided into the same number of parts so that nodal connectivity intact.

The rigid plates of $10 \mathrm{~mm}$ thick are placed at every face of the beams/columns to transfer the loads uniformly. From analysis of $\mathrm{G}+4$ storey RCC structure in ETABS, the displacements are found out at every one metre distance from the joint. So the displacement values obtained from the ETABS are given as boundary conditions at central nodes of the rigid plates placed on every face of beams and columns.

The loads are applied at the central node of the faces of the beams and columns. A rigid plate of $10 \mathrm{~mm}$ thick is placed on the faces of beams and columns to transfer the loads to the structure uniformly. The interior beam column joint at the fourth storey level is taken and the axial force which is coming to the column is applied here and the shear force and bending moments are applied to the beams.

TABLE I.

DisPLACEMENTS AND ROTATIONS OF THE INTERIOR BEAMCOLUMN JOINT

\begin{tabular}{|c|c|c|c|r|r|c|}
\hline $\begin{array}{c}\text { Displacem } \\
\text { ents(mm) } \\
\text { and } \\
\text { rotations(r } \\
\text { adian) }\end{array}$ & $\mathrm{X}$ & $\mathrm{Y}$ & $\mathrm{Z}$ & $\mathrm{R}_{\mathrm{x}}$ & $\mathrm{R}_{\mathrm{y}}$ & $\mathrm{R}_{\mathrm{z}}$ \\
\hline $\begin{array}{c}\text { Top } \\
\text { beam }\end{array}$ & 0.24 & 3.445 & 0.073 & 0 & 0 & 0 \\
\hline $\begin{array}{c}\text { Bottom } \\
\text { beam }\end{array}$ & 0.017 & - & 0.082 & 0 & 0 & 0 \\
\hline $\begin{array}{c}\text { Right } \\
\text { column }\end{array}$ & 0.199 & - & 0.075 & - & 0 & 0 \\
\hline $\begin{array}{c}\text { At } \\
\text { junction }\end{array}$ & 0.124 & -185 & 0.139 & 0.001 & 0 & 0 \\
\hline $\begin{array}{c}\text { Left } \\
\text { column } \\
\text { beam }\end{array}$ & 0.130 & - & 0.081 & 0.001 & 0 & 0 \\
\hline $\begin{array}{c}\text { Front } \\
\text { beam }\end{array}$ & 0.126 & - & 0.072 & 0 & 0 & - \\
\hline & 4.215 & - & 0.083 & 0 & 0 & 0 \\
\hline
\end{tabular}


TABLE II.

AXIAL FORCES TO THE COLUMN.

\begin{tabular}{|c|c|}
\hline Location & Axial force(N) \\
\hline Top column & -534147 \\
\hline Bottom column & 1047983 \\
\hline
\end{tabular}

TABLE III.

SHear Force And Bending Moment To The BeAm.

\begin{tabular}{|c|c|c|}
\hline Location & $\begin{array}{c}\text { Shear } \\
\text { force(N) }\end{array}$ & $\begin{array}{c}\text { Bending } \\
\text { moment(N.mm) }\end{array}$ \\
\hline Right beam & -121540 & -93880 \\
\hline Left beam & 121540 & 93880 \\
\hline Front beam & -125290 & -103430 \\
\hline Back beam & 125290 & 103430 \\
\hline
\end{tabular}

In the post-processer menu the results are obtained. In this present problem, displacements and the strain energies are to be known to study the behaviour of the exterior beamcolumn joint.

The FEM analysis of interior beam-column joint is completed. Now the main objective of the study is to replace the beam-column joint with the equivalent beam-strut elements. Here the replacing of beam-column junction is based on the strain energy concepts. The strain energy obtained with concrete in the beam-column junction location with proposed beam-strut elements is compared.

For the replacing of the beam-column joint with the equivalent beam/struts, keeping the junction portion empty here after, place the equivalent beam/strut elements at the junction portion. The beam elements are placed parallel to the beam and column orientation at the joint. And the strut elements are placed joining the midpoints of beam and column surfaces.

By taking the beam as element, the beams are drawn initially with $100 \times 100 \mathrm{~mm}$ dimensions at the beam-column interface. To draw the beams, beam 188 element is taken. Beam 188 element is linear two nodded in 3-D. It has six degrees of freedom at each node; translations in the $\mathrm{x}, \mathrm{y}$ and $\mathrm{z}$ directions and rotations about the $\mathrm{x}, \mathrm{y}$ and $\mathrm{z}$ directions. The struts are drawn with Link 180 element. Link 180 is a 3D spar element that is useful for variety of engineering applications. The element can be used for modelling of trusses links, springs etc. Link 180 element is a uniaxial tension compression element with three degrees of freedom at each node: translations in the nodal $\mathrm{x}, \mathrm{y}$ and $\mathrm{z}$ directions.

The element is defined by two nodes and the cross sectional area of the link element is defined by the sectional type command. The area of link is given as $10000 \mathrm{~mm}^{2}$. If the strain energy of the model with the equivalent beam/strut elements having $10000 \mathrm{~mm}^{2}$ area is matching with the strain energy of the model without struts then the equivalent beam/strut area can be fixed as $10000 \mathrm{~mm}^{2}$.

To model the equivalent beam/strut elements the material properties are same as beam-column joint. Here the equivalent beam-strut element is assumed like a concrete material and the properties are given. The young's modulus of beam-strut is given as $25 \mathrm{e} 3$ and the poisons ratio is given as 0.3 .

After modelling of the interior beam-column joint with the equivalent beam-strut elements, the boundary conditions and the loads of same as the interior beam-column joint without struts are applied. The struts are kept in three directions $\mathrm{x}, \mathrm{y}$ and $\mathrm{z}$ directions.

The strain energy calculations with proposed equivalent beam/strut element are found to be less when the beamcolumn joint has full concrete mass. The ratio of strain energy with full concrete mass to the strain energy with equivalent beam/strut model is taken as the penalty factor for the particular beam column joint the dimensions of beam-strut element are revised upward by multiplying with the original beam/strut elements with the penalty factor. These results can obtain more rational beam-strut dimensions. However, the equivalent beam/strut elements cannot replace the action of full concrete mass as the discrete element frame work is flexible in comparison to the full concrete mass.

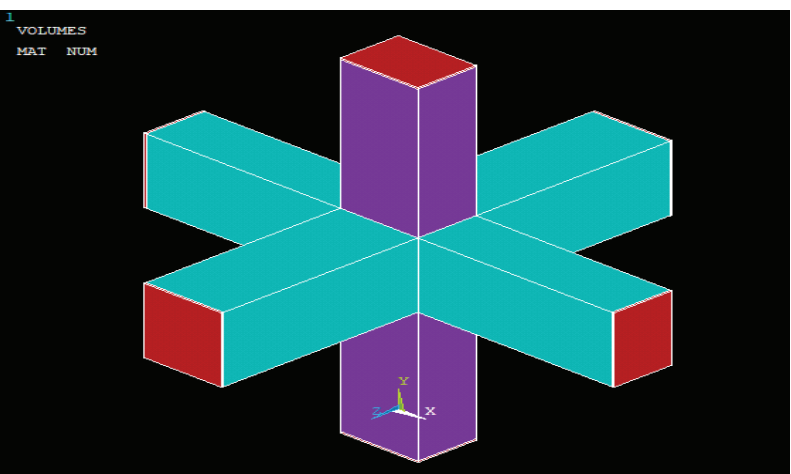

Figure 2. Interior beam-column joint without struts

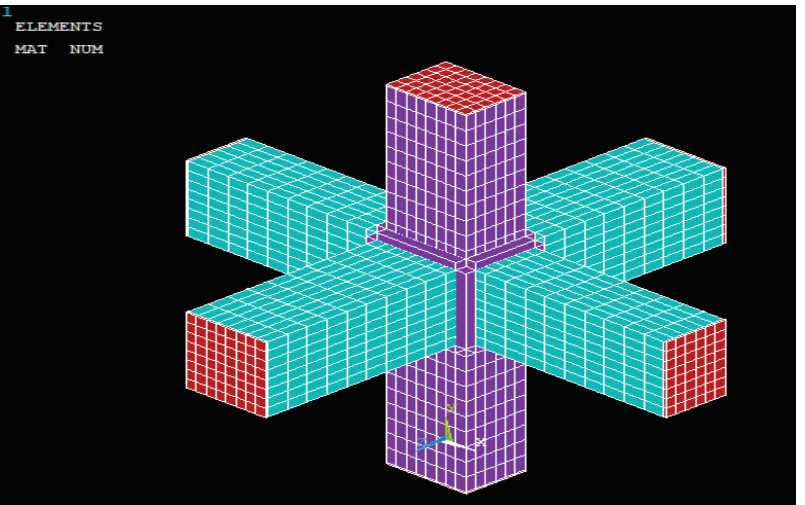

Figure 3. Interior beam-column joint with struts 
The following models are developed by using the above procedure.

1) Exterior beam-column joint

2) Corner beam-column joint

3) Interior beam-column joint varying grades of concrete and dimensions of beams/columns

4) Exterior beam column joint varying grades of concrete and dimensions of beams/columns

5) Corner beam column joint varying grades of concrete and dimensions of beams/columns

Total 18 models are developed and analysed.

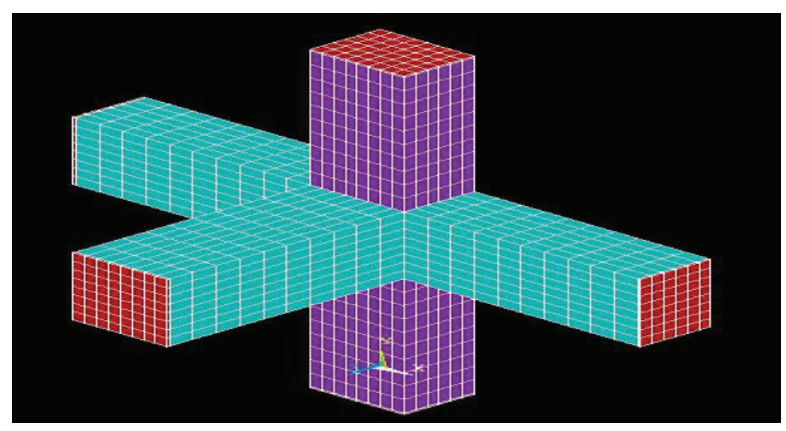

Figure 4. Exterior beam-column joint without struts

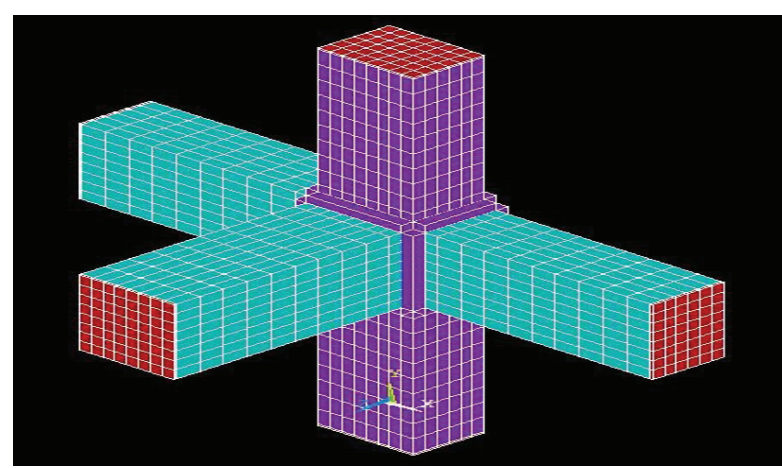

Figure 5. Exterior beam-column joint with struts

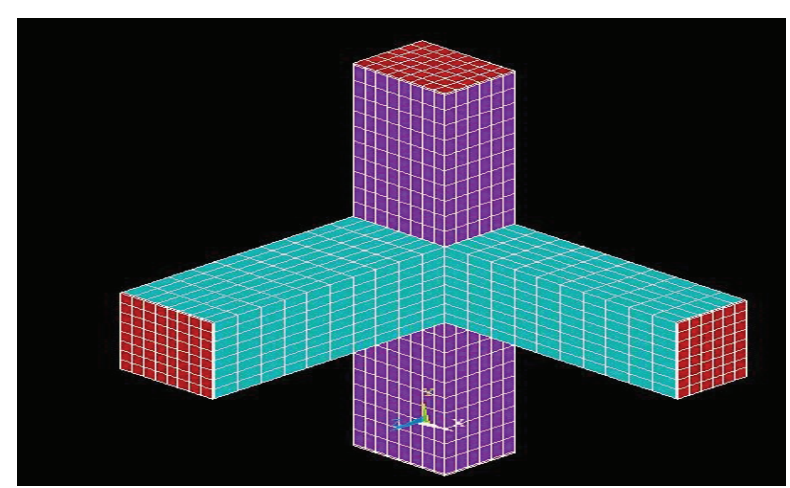

Figure 6. Corner beam-column joint without struts

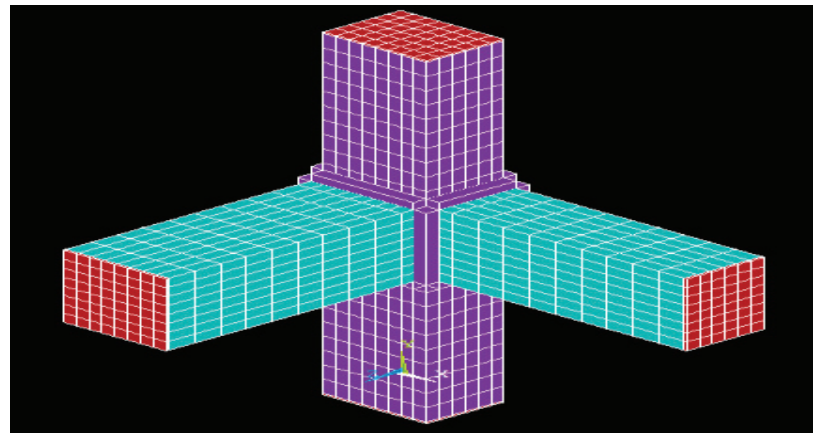

Figure 7. Corner beam-column joint with struts

\section{RESults And Discussions}

Results

After having analysed the RCC beam-column joints using FEM approach in ANSYS package, the results are obtained for maximum displacements and strain energies are tabulated below. The studies are carried out firstly with the full concrete beam-column joints and then replacing of junction portion with the equivalent beam/strut elements.

1) The analysis of beam-column joint having beam cross sectional dimensions as $300 \times 400 \mathrm{~mm}$ and $400 \times 500 \mathrm{~mm}$ and the column cross sectional dimensions as $300 \mathrm{X} 400$ $\mathrm{mm}$. And the grade of concrete of beams and columns is same that is M25. Initially the dimensions of equivalent beam/strut elements are taken as $100 \mathrm{X} 100 \mathrm{~mm}$.

TABLE IV.

THE RESUlts OF THE INTERIOR BEAM-COLUMN JOINT

\begin{tabular}{|c|c|c|}
\hline Results & $\begin{array}{c}\text { Without } \\
\text { struts }\end{array}$ & $\begin{array}{c}\text { With } \\
\text { struts }\end{array}$ \\
\hline $\begin{array}{c}\text { Maximum } \\
\text { Displacements(mm) }\end{array}$ & 4.24114 & 4.24113 \\
\hline $\begin{array}{c}\text { Strain } \\
\text { energy(N.mm) }\end{array}$ & 224042 & 180572 \\
\hline
\end{tabular}

Penalty factor $=1.240$

The revised dimensions of the equivalent beam/strut elements are $111 \mathrm{~mm}$ X $111 \mathrm{~mm}$.

TABLE V.

THE Results Of THE EXTERIOR BEAM-COLUMN JOINT

\begin{tabular}{|c|c|c|}
\hline Results & $\begin{array}{c}\text { Without } \\
\text { struts }\end{array}$ & $\begin{array}{c}\text { With } \\
\text { struts }\end{array}$ \\
\hline $\begin{array}{c}\text { Maximum } \\
\text { Displacements(mm) }\end{array}$ & 3.5656 & 3.56533 \\
\hline $\begin{array}{c}\text { Strain } \\
\text { energy(N.mm) }\end{array}$ & 141464 & 97599.4 \\
\hline
\end{tabular}

Penalty factor $=1.449$

The revised dimensions of the equivalent beam/strut elements are $120 \mathrm{~mm} \mathrm{X} 120 \mathrm{~mm}$. 
TABLE VI.

THE Results Of THE CORNER BEAM-COLUMN JOINT

\begin{tabular}{|c|c|c|}
\hline Results & $\begin{array}{c}\text { Without } \\
\text { struts }\end{array}$ & $\begin{array}{c}\text { With } \\
\text { struts }\end{array}$ \\
\hline $\begin{array}{c}\text { Maximum } \\
\text { Displacements(mm) }\end{array}$ & 2.59199 & 2.62161 \\
\hline $\begin{array}{c}\text { Strain } \\
\text { energy(N.mm) }\end{array}$ & 71401.6 & 32893.9 \\
\hline
\end{tabular}

Penalty factor $=2.170$

The revised dimensions of the equivalent beam/strut elements are $147 \mathrm{~mm} \mathrm{X} 147 \mathrm{~mm}$.

2) The analysis of beam-column joint having beam cross sectional dimensions as $300 \mathrm{X} 400 \mathrm{~mm}$ and $400 \times 500 \mathrm{~mm}$ and the column cross sectional dimensions as $300 \mathrm{X} 400 \mathrm{~mm}$. And the grade of concrete of beams as M20 and columns as M40 are taken. Initially the dimensions of equivalent beam/strut elements are taken as $100 \mathrm{X} 100 \mathrm{~mm}$.

TABLE VII.

THE RESUlts OF THE INTERIOR BEAM-COLUMN JOINT

\begin{tabular}{|c|c|r|}
\hline Results & $\begin{array}{c}\text { Without } \\
\text { struts }\end{array}$ & $\begin{array}{r}\text { With } \\
\text { struts }\end{array}$ \\
\hline Maximum & 4.64301 & 4.6429 \\
Displacements(mm) & & 7 \\
\hline Strain & 112102 & 87215 \\
\hline energy(N.mm) & & \\
\hline
\end{tabular}

Penalty factor $=1.285$

The revised dimensions of the equivalent beam/strut elements are $113 \mathrm{~mm}$ X $113 \mathrm{~mm}$.

TABLE VIII.

The Results Of THE EXTERIOR BEAM-COLUMN JOINT

\begin{tabular}{|c|c|c|}
\hline Results & $\begin{array}{c}\text { Without } \\
\text { struts }\end{array}$ & $\begin{array}{c}\text { With } \\
\text { struts }\end{array}$ \\
\hline $\begin{array}{c}\text { Maximum } \\
\text { Displacements(mm) }\end{array}$ & 3.377781 & 3.77747 \\
\hline $\begin{array}{c}\text { Strain } \\
\text { energy(N.mm) }\end{array}$ & 78173 & 50612.5 \\
\hline
\end{tabular}

Penalty factor $=1.544$

The revised dimensions of the equivalent beam/strut elements are $124 \mathrm{~mm} \mathrm{X} 124 \mathrm{~mm}$.

TABLE IX.

The Results Of THE CORNER BEAM-COLUMn JOINT

\begin{tabular}{|c|c|c|}
\hline Results & $\begin{array}{c}\text { Without } \\
\text { struts }\end{array}$ & $\begin{array}{c}\text { With } \\
\text { struts }\end{array}$ \\
\hline $\begin{array}{c}\text { Maximum } \\
\text { Displacements(mm } \\
\text { ) }\end{array}$ & 2.59465 & 2.61702 \\
\hline $\begin{array}{c}\text { Strain } \\
\text { energy(N.mm) }\end{array}$ & 46059.4 & 22367.2 \\
\hline
\end{tabular}

Penalty factor $=2.059$

The revised dimensions of the equivalent beam/strut elements are $143 \mathrm{~mm} \mathrm{X} 143 \mathrm{~mm}$.
3) The analysis of beam-column joint having beams cross sectional dimension as $400 \times 500 \mathrm{~mm}$ and the column cross sectional dimensions as $400 \times 400 \mathrm{~mm}$. And the grade of concrete of beams and columns is same that is M25. Initially the dimensions of equivalent beam/strut elements are taken as $100 \mathrm{X} 100 \mathrm{~mm}$.

TABLE X.

THE RESUlts OF THE INTERIOR BEAM-COLUMN JOINT

\begin{tabular}{|c|c|c|}
\hline Results & $\begin{array}{c}\text { Without } \\
\text { struts }\end{array}$ & $\begin{array}{c}\text { With } \\
\text { struts }\end{array}$ \\
\hline $\begin{array}{c}\text { Maximum } \\
\text { Displacements(m } \\
\text { m) }\end{array}$ & 49 & 3.62547 \\
\hline $\begin{array}{c}\text { Strain } \\
\text { energy(N.mm) }\end{array}$ & 73572 & 56313.4 \\
\hline
\end{tabular}

Penalty factor $=1.306$

The revised dimensions of the equivalent beam/strut elements are $114 \mathrm{~mm} \mathrm{X} 114 \mathrm{~mm}$

TABLE XI.

THE Results Of THE EXTERIOR BEAM-COLUMN JOINT

\begin{tabular}{|c|c|c|}
\hline Results & $\begin{array}{c}\text { Without } \\
\text { struts }\end{array}$ & $\begin{array}{c}\text { With } \\
\text { struts }\end{array}$ \\
\hline $\begin{array}{c}\text { Maximum } \\
\text { Displacements(mm) }\end{array}$ & 2.9361 & 2.93565 \\
\hline $\begin{array}{c}\text { Strain } \\
\text { energy(N.mm) }\end{array}$ & 51606 & 34636.7 \\
\hline
\end{tabular}

Penalty factor $=1.489$

The revised dimensions of the equivalent beam/strut elements are $122 \mathrm{~mm} \mathrm{X} 122 \mathrm{~mm}$

TABLE XII.

The Results Of THE CORNER BEAM-COLUMn JOINT

\begin{tabular}{|c|c|c|}
\hline Results & $\begin{array}{c}\text { Without } \\
\text { struts }\end{array}$ & $\begin{array}{c}\text { With } \\
\text { struts }\end{array}$ \\
\hline $\begin{array}{c}\text { Maximum } \\
\text { Displacements(mm) }\end{array}$ & 1.99536 & 1.98692 \\
\hline $\begin{array}{c}\text { Strain } \\
\text { energy(N.mm) }\end{array}$ & 27800.4 & 12598.2 \\
\hline
\end{tabular}

Penalty factor $=2.206$

The revised dimensions of the equivalent beam/strut elements are $148 \mathrm{~mm} \mathrm{X} 148 \mathrm{~m}$.

\section{Discussions}

The modelling of the beam-column joint with equivalent beam/strut elements is carried out as given under. The struts are placed joining the central points of the beam faces running parallel to the beams in both the directions as well as the central points of the column faces above and below, running parallel to the column axis. Due to the applied loads on the beam-column joint making use of ANSYS package the finite element analysis of the model using linear elastic analysis module of ANSYS is carried out. The strain energy stored within the beam-column joint portion of the concrete 
mass is evaluated. Next, the RC mass in the beam-column joint portion is replaced with the equivalent beam-strut model and the analysis is once again carried out. Here, an arbitrary size of beam-strut element is used. The strain energy stored by the beam-strut element is worked out and is compared with that obtained due to total concrete mass. The size of the beam-strut elements are revised upward using a penalty factor, defined later in the specimen calculation chapter.

The intension of the present study is to replace the beamcolumn joint in a structural frame work with the equivalent strut frame work to carry out the structural analysis. By this it is intended to use the same software package used for the skeletal frame work to the one with the beam-column joints also.

From the results, the strain energy of beam-column joint is always greater compared to the strain energy of the beamcolumn joint with the equivalent beam/strut elements. As compared to the three beam-column joints, the interior one is much stronger than the other two.

\section{CONClusions}

Based on the limited studies carried out on beam-column joint models using finite element analysis, the following conclusions are drawn:

1. The equivalent beam/strut dimensions were found to be $16.8 \%$ larger for the interior joints as compared to the exterior joints, when the concrete mix for the beams and columns is the same.

2. When the grade of concrete used for columns is much superior to the grade used for beams, the sectional dimensions of the equivalent beam/strut elements are larger as compared to the ones with same concrete mix for both beams and columns, all other conditions remain the same.

3. When the cross sectional dimensions of the beams are increased the equivalent beam/strut dimensions were found to be larger by $14.52 \%$ between the interior joint and the exterior joint.

\section{REFERENCES}

[1] Hiroshi Noguchi and Kazuhiro Uchida, "The FEM analysis of hybrid structural frames with reinforced concrete columns and steel beams", ASCE (2004).

[2] K.R. Bindhu, P.M. Sukumar and K.P. Jaya, "Performance of exterior beam-column joints under seismic type loading", ISET (2009).

[3] P. Rajaram, A. Murugesan and G.S.Thirugnanam, "Experimental study of interior beam column joint subjected to cyclic loading", ISET (2010).

[4] Bing Li and Sudhakar A. Kulkarni, "Seismic behaviour of RC exterior wide beam-column joints", ASCE (2010)
[5] Mohammad S. Alhaddad, Nadeem A. Siddiqui, Aref A. Abadel, Saleh H. Alsayed and Yousef A. Al-Salloum,

"Numerical Investigations on the Seismic Behaviour of FRP and TRM Upgraded RC Exterior Beam-Column Joints", ASCE (2012).

[6] S. S. Patil, S. S. Manekari "Analysis of reinforced beamcolumn joint subjected to monotonic loading", IJEIT (2013)

[7] Syed Sohailuddin S and M G Shaikh, "Finite element modelling of reinforced concrete beam column joint using ANSYS", IJSCER (2013).

[8] Bing Li, M.ASCE and Chee Lai Leong, "Experimental and Numerical Investigations of the Seismic Behaviour of HighStrength Concrete Beam-Column Joints with Column Axial Load", ASCE (2014).

[9] C.Geethajali, Dr.P.Muthu Priya, Dr.R.Venkatasubramani, "Behaviour of HFRC Exterior Beam-Column Joints under Cyclic loading", IJSTER (2014).

[10] Shabana T S, Dr. K.A Abubaker, Renny Varghees, "Finite Element Analysis of Beam Column Joint with GFRP under Dynamic Loading”, IJETT (2015).

[11] Miss.Kane Kruthika R and Miss. Samarth Gauri V, "Study of Behaviour \& Strenghening of Beam-Column Joint", IJRITCC (2017).

[12] Dr. S. R. Uma, Prof. A. Meher Prasad, "Seismic behaviour of beam column joints in RC moment resisting frames". 